\title{
ANALYSIS OF MONITORING OF CONNECTION BETWEEN REENGINEERING ECONOMIC PARAMETERS IN SMALL AND MEDIUM ENTERPRISES USING THE METHOD OF CREATING OPTIMAL QUESTIONNAIRE
}

\author{
${ }^{1}$ Slobodan Stefanović, ${ }^{2}$ Dragoslav Ilić, ${ }^{3}$ Nataša Bogavac-Cvetković, ${ }^{4}$ Radica Pavlović \\ ${ }^{1}$ High School of Applied Professional Studies of Vranje, Serbia. slobodanstef@gmail.com \\ 2JKP "Water" Zajecar, Serbia. dragoslav.dragi@gmail.com \\ ${ }^{3}$ Faculty for Business Studies, Belgrade, Serbia. ncvetkovic@megatrend.edu.rs \\ ${ }^{4}$ Faculty for Business Studies, Požarevac, Serbia. rpavlovic@ megatrend.edu.rs
}

\begin{abstract}
The analysis of this type of connecting economic parameters by using reengineering is reflected through the formation of an Optimal questionnaire $G_{o}$ which allows connecting the $\mathrm{N}$ parameters by the question of connection between $\sum_{m \in M} q_{m}=\sum_{l \in L} h_{l}$, with the basis $a_{m}$ and value $c_{l}$ so the divergence stem of economic effects with the root $x_{o}$ is as follows : $N=\sum_{m \in M} q_{m} X\left(a_{m}-1\right)+1$, and their peaks are arranged into a descending set in terms of their ranks.

Key words: Questionnaire algorithm, Questionnaire Graph,parameters of reengineering monitoring.
\end{abstract}

1. Introduction - qestionnaire algorithm

The publication of this kind of questionnaire can be presented through Algorithm (George WR (1990)).

Algorithm: A questionnaire has been given regarding the connection between reengineering economic parameters $G$ differentiating set $E$ from $N$ economic parameters $y_{i}$ with the weights of connection $p\left(y_{i}\right), i=1,2,3, \ldots, N$, the help of $|Q|$ questions imposing when it comes to their connection where the questions $q_{m}$ have the bases $a_{m},(m \in M)$ i $h_{l}$ questions have the values $c_{l},(l \in L) i$ (Adamović Z., Stefanović S., (2008)). The transformation of the initial questionnaire on the connection between economic parameters of re-engineering $G$ should be transformed into an optimal questionnaire $G_{o}$.

1. Two lists are formed using the weight of economic parameters and bases and values of the questions from the questionnaire on the connection of parameters $G$, being: list 1 weights $p\left(z_{k}\right) \leq p\left(z_{k+1}\right), k=1,2, . . N$, and list $2-\mathrm{a}$ pair of bases and values of connection questions $\left(a_{j}, c_{j}\right)$ where the bases are arranged into a non-descending set $\left(a_{j}\right) \leq\left(a_{j+1}\right), j=1,2, . . N$, and the values in the ascending set are $\left(c_{j}\right) \geq\left(c_{j+1}\right), j=1,2, . .|Q|$. For the analysis we usually accept $j+1$.

2. The pair $2\left(a_{j}, c_{j}\right)$ from the list refers to the questions of connection beween economic parameters $x_{i}$ of the optimal questionnaire $G_{o}$, i.e., it is regarded as follows: $a\left(x_{j}\right)=a_{j} \mathrm{i}$ $c\left(x_{j}\right)=c_{j} . \quad a_{j}$ of the first weights are erased from the list 1 and are accepted as the weights of the first adherents of the questions of connection between economic parameters $x_{j}$. Defining the weight of the questions of connection $x_{j}$ is: $p\left(x_{j}\right)=\sum_{k=1}^{a_{j}} p\left(z_{k}\right)$.

3. List 1 is modified, keeping the unerased weights in it and including the question weight $p\left(x_{j}\right)$. Those weights are arranged into a non-descending set. They check the 
accurateness of $j$ : in case of $j \leq|Q|$, then they increase $j$ to 1 and return to $p 2$; in case of $j \geq|Q|$ then they cross over to $p 4$.

4. The finishing of the optimal questionnaire $G_{O}$ formation.

The presented methodology for the analysis of the connection between the reengineering economic parameters shall be carried out on the re-engineering model. The general algorithm model shall be formed on the basis of economic parameters of groups 1,2,3. It shall serve as the initial questionnaire on the connection between re-engineering economic parameters $G$. For its formation we shall use the groups of parameters with weight records, determined on the grounds of the significance in the following table, and they shall include their values from 0 to 1 regarding the significancies in the process of re-engineering in the candidate's opinion (Bateson J (2002)).

Questionnaires $G_{i}$ are presented in Table 1 for the three parameters of the groups: $\underline{x_{1}}\left(x_{0}, x_{1}, x_{2}\right), \quad \underline{x_{2}}\left(x_{3}\right), \quad \underline{x_{3}}\left(x_{4}\right)$ for 24 events $\left(y_{1}, y_{2}, \ldots . . y_{24}\right)$. The events' and questions' weights are shown parallelly with the corresponding peaks, numbers without brackets, and questions' values with numbers in brackets (picture 1.). The events' values were chosen regarding the priorities of re-engineering parameters' significancies in the order shown in Table 1., while the candidate himself has suggested the significancies' values based on his experience gained while monitoring the reengineering process in small and medium enterprises in our country (Bonn MA (2003)).

\section{Group of algorithm}

Group 1) The first and third type in Table 1. are comprised by: Total expenses $\sum_{i=1}^{5} U K N_{\text {bifore.costs }}$ arising in the course of applying the research subject and are defined as the bearers of economic parameters in the carrying out of the re-engineering, are expressed by the adding up of parameters (Sefanović S., (2010)),

$$
\begin{aligned}
& \sum_{i=1}^{5} U K N_{\text {bifore.costs }}=\left(N E E_{N O}=N E E_{N P}\right)+N E E_{N P}+ \\
& N E E_{S P}+N E E_{P R}+N E E_{P P^{+}} \quad N E E_{N S R} .
\end{aligned}
$$

The marks of this group of parameters are: economic parameters created by the completion and documenting of the detailed re-engineering project comprising of: a new organisation model in the enterprise as well as the characteristics and roles of new jobs within that new organization; /parameter $N E E_{N O}=N E E_{N P}, \quad N E E_{N O^{-}}$parameter of the economic effect bearer relating to the new organization model and it exclusively depends on $N E E_{N P}$ - parameter of the economic effect bearer relating to the characteristics of new jobs within the new organization of small and medium enterprises by applying re-engineering; Economic parameters created by carrying out the system support in the new organization in small or medium enterprises; /parameter $N E E_{S P}$ parameter of the economic effect bearer relating to the carrying out of the system support; economic parameters created by carrying out the "pilot solution", i.e. the system support within the new organization of small or medium enterprise by testing the enterprises through applying the reengineering on small-scale production; /parameter $N E E_{P R}$ - parameter of the economic effect bearer relating to the carrying out of the "pilot solution"; Economic parameters which are general and are related to the introduction of the employees with the planned changes and the application of the plan during the re-engineering carrying out in phases; /parameter $N E E_{P P}$ parameter of the economic effect bearer relating to the invested time needed for the carrying out of the planned changes and the application of the plan during the carrying out of re-engineering in phases in the enterprise; Economic parameters which are general and relate to the training of employees for the new process and the new system of work with the planned changes and application of the plan in the process of reengineering carrying out in phases; /parameter $N E E_{N S R}$ - parameter of the economic effect bearer relating to the expenses arising in the course of 
the employees' training for the new system of work; Economic parameters of the financial recovery of small or medium enterprises $N E E_{F S}$, by introducing re-engineering comprising of the introduction of an integral logic system into a small or medium enterprise; Economic parameters securing the functioning of entrepreneurship for the carrying out of reengineering $N E E_{K P} ;$ Economic parameters securing the processes of functioning of all structures and quality systems in small and medium enterprises by introducing reengineering $N E E_{S K} ;$ Economic parameters securing the competitiveness of the products' prices on the market $N E E_{C P}$ created in the conditions of production applying the reengineering.

Table 1. Values of events in optimal questionnaires $G_{i}$ for three parameters of groups

\begin{tabular}{|c|c|c|c|c|c|}
\hline Group & \multicolumn{5}{|c|}{ Events } \\
\hline ters & & & & & \\
\hline \multirow[t]{3}{*}{$\underline{1}$} & $\begin{array}{c}x_{0}\left(\sum_{i=1}^{5} U K N_{\text {pred.troskovi }}\right) \\
1,0\end{array}$ & $\begin{array}{c}y_{1}=N E E_{N P} \\
0,5\end{array}$ & $\begin{array}{c}y_{2}=N E E_{S P} \\
0,2\end{array}$ & $\begin{array}{c}y_{3}=N E E_{P R} \\
0,1\end{array}$ & $\begin{array}{cc}y_{4}=N E E_{P P}, & y_{5}= \\
0,1 & 0,1\end{array}$ \\
\hline & $\begin{array}{c}x_{1}\left(R_{P P}\right) \\
1,0\end{array}$ & $\begin{array}{c}y_{6}=I N T_{C M} \cdot \sum_{i=1}^{n} P_{i} \\
0,25\end{array}$ & $\begin{array}{c}y_{7}=I N T_{C M} \cdot \sum_{i=1}^{n} T_{j} \\
0,25\end{array}$ & $\begin{array}{c}y_{8}=I N T_{C M} \cdot \sum_{i=1}^{n} I_{k} \\
0,25\end{array}$ & $\begin{array}{c}y_{9}=I N T_{C M} \cdot \sum_{i=1}^{n} C_{i} \\
0,25\end{array}$ \\
\hline & $\begin{array}{c}x_{2}\left(N E E_{S K}\right) \\
1,0\end{array}$ & $\begin{array}{c}y_{10}=N E E_{F S}, \\
0,25\end{array}$ & $\begin{array}{c}y_{11}=N E E_{K P} \\
0,25\end{array}$ & $\begin{array}{c}y_{12}=N E E_{S K} \\
0,25\end{array}$ & $\begin{array}{c}y_{13}=N E E_{C P} \\
0,25\end{array}$ \\
\hline$\underline{2}$ & $\begin{array}{r}x_{3}(C E N E) \\
1,0 \\
\end{array}$ & $\begin{array}{c}y_{14}=T R_{P} \\
0,25\end{array}$ & $\begin{array}{c}y_{15}=V N M \\
0,25\end{array}$ & $\begin{array}{c}y_{16}=C N \\
0,25\end{array}$ & $\begin{array}{c}y_{17}=P T \\
0,25\end{array}$ \\
\hline \multirow{2}{*}{$\underline{3}$} & \multirow{2}{*}{$\begin{array}{c}x_{4}(V E F) \\
1,0\end{array}$} & $\begin{array}{c}y_{18}=R_{M} \\
0,25\end{array}$ & $\begin{array}{c}y_{19}=R_{N R} \\
0,25\end{array}$ & $\begin{array}{c}y_{20}=R_{M d \mid} \\
0,25\end{array}$ & $\begin{array}{c}y_{21}=R_{P} \\
0,25\end{array}$ \\
\hline & & $\begin{array}{c}y_{22}=R_{P K P} \\
0,33\end{array}$ & $\begin{array}{c}y_{23}=R_{E F F} \\
0,33\end{array}$ & $\begin{array}{c}y_{24}=R_{V Z P} \\
0,33\end{array}$ & \\
\hline
\end{tabular}

NOTE: Meanings of re-engineering group parameters' symbols (Sefanović S., (2010)).

The second type of parameters in Table 1. includes the Cartesian product of the Computer Integrated Manufacturing (CIM) integration rules - of the enterprise and the given set of components influencing the re-engineering carrying out in the following form (Stefanović S., Cvejić R. (2010)):

$$
R_{P P} \rightarrow I N T_{C I M} \cdot\left(\sum_{i=1}^{n} P_{i}+\sum_{i=1}^{n} T_{j}+\sum_{i=1}^{n} I_{k}+\sum_{i=1}^{n} C_{l}\right)
$$

where: $R_{P P}$ - is the integration rules product; CIM - Computer Integrated Manufacturing business activities (Computer Integrated Manufacturing); $\sum_{i=1}^{n} P_{i}$ - the sum of new competitive products (or the sum of new production programmes); $\sum_{i=1}^{n} T_{j}$ - the sum of new high production technologies; $\sum_{i=1}^{n} I_{k}$ the sum of new high information technologies ; $\sum_{i=1}^{n} C_{l}$ - the sum of high communication technologies (networked business people).

Group 2 This type of Table 1. includes the following parameters of the market and prices as manufacturing factors analysis as the basis for the re-engineering application, being: production costs, i.e. the value of the goods that needs to be converted into money $T R_{P}$; the value of the 
monetary material used to express the value of the goods $V N M$; the value of the price measure used as the value measuring unit $C N$; the ratio of supply to demand $P T$.

Group 3 Table 1 includes the noneconomic factors $V E F$ i.e. the general financial parameters of small and medium enterprise functioning which causatively influence the carrying out of re-engineering under the conditions of transition and they comprise of: process management $\left(R_{P R}\right)$; Luirao Marketing function $\left(R_{M}\right)$; scientific and research function $\left(R_{N R}\right)$; the function of management approach in production planning $\left(R_{M d \mid}\right)$; the function of financial planning for the purpose of enterprise development $\left(R_{P}\right)$; the function of planning and controlling of business $\left(R_{P K P}\right)$; economic and financial function $\left(R_{E F F}\right)$ and the function of connecting salaries with the performances $\left(R_{V Z P}\right)$.

Picture 1. shows the graph of connection between re-engineering parameters for the formation of algorithm and the monitoring of its carrying out in small and medium enterprises' organization.

\section{Relization of algorithm formation}

Relations for the formation of algorithm questionnaire graph are as follows (Stefanović S., and sar.(2007)).

$\underline{\text { Algorithm }} A_{1}$ for questionnaire $G_{1}$

$\begin{array}{ccc}\text { STEP } & 1: \quad \text { Record1: } & \text { relations } \\ & \left(y_{1}, y_{2}, \ldots \ldots y_{13}\right)=\text { values } & \end{array}$

$(0,5 ; 0,2 ; 0,1 ; 0,1 ; 0,1 ; 0,25 ; 0,25 ; 0,25 ; 0,25$;

$0,25 ; 0,25 ; 0,25 ; 0,25)$;

Record 2: relations

$\left(\begin{array}{cc}x_{0} & 1 \\ 1 & 3\end{array}\right)\left(\begin{array}{ll}1 & 1 \\ 3 & 3\end{array}\right)\left(\begin{array}{cc}1 & x_{1} \\ 3 & 1\end{array}\right)\left(\begin{array}{cc}x_{1} & 1 \\ 1 & 3\end{array}\right)\left(\begin{array}{cc}1 & x_{2} \\ 3 & 1\end{array}\right)\left(\begin{array}{cc}x_{2} & 1 \\ 1 & 3\end{array}\right)$.

For the two relations' adherents we will note the first and last weight $\rho_{p}(0,5)$ i $\rho_{k}(0,25)$.

STEP 2: The total mid value of algorithm weight in step 1 is: $p(1)=\frac{0,5+0,25}{2}=0.375$ that's the value of the question of connection between reengineering coefficients for group (1) parameter.

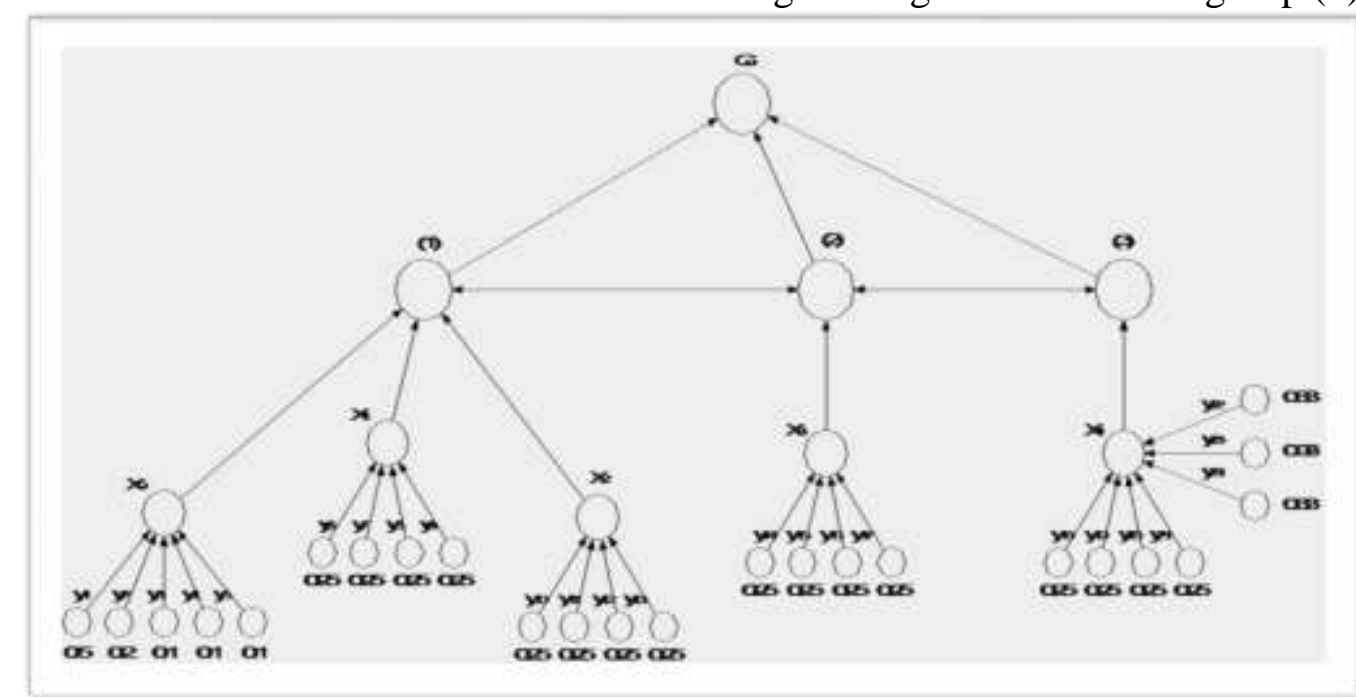

Picture 1. Questionnaire graph (General model of algorithm for re-engineering monitoring) (Sefanović S., (2010))

\section{$\underline{\text { Algorithm }} A_{2} \underline{\text { for questionnaire }} G_{2}$} STEP

Record1:relations

$$
\left(y_{14}, y_{15}, y_{16}, y_{17}\right)=\text { values }
$$

$(0,25 ; 0,25 ; 0,25 ; 0,25)$;

3: For the two relations' adherents we will note the first and last weight $\rho_{p}(0,25)$ i $\rho_{k}(0,25)$. 
STEP 4: The total mid value in algorithm in step 3 is: $p(2)=\frac{0,25+0,25}{2}=0.25$ that's that's the value of the question of connection between re-engineering coefficients for group (2) parameter.

\section{Algorithm $A_{3}$ for questionnaire $G_{3}$} STEP

$$
\begin{aligned}
& \text { Record1:relations } \\
& \left(y_{18}, y_{19}, y_{20}, y_{21}\right)=\text { values }
\end{aligned}
$$

$(0,25 ; 0,25 ; 0,25 ; 0,25)$;

For the two relations' adherents we will note the first and last weight $\rho_{p}(0,25)$ i $\rho_{k}(0,25)$.

STEP 6: The total mid value in algorithm in step 5 is: $p(2)=\frac{0,25+0,25}{2}=0.25$ that's the value of the question of connection between re-engineering coefficients for the group(3 - I group) .

STEP 7: Record 1: relations $\left(y_{22}, y_{23}, y_{24}\right)=$ values

$$
(0,33 ; 0,33 ; 0,33) \text {; }
$$

For the two relations' adherents we will note the first and last weight $\rho_{p}(0,33)$ i $\rho_{k}(0,33)$.

STEP 8: The total mid value of algorithm weight in step 7 je: $p(2)=\frac{0,33+0,33}{2}=0.33$ that's the value of the question of connection between re-

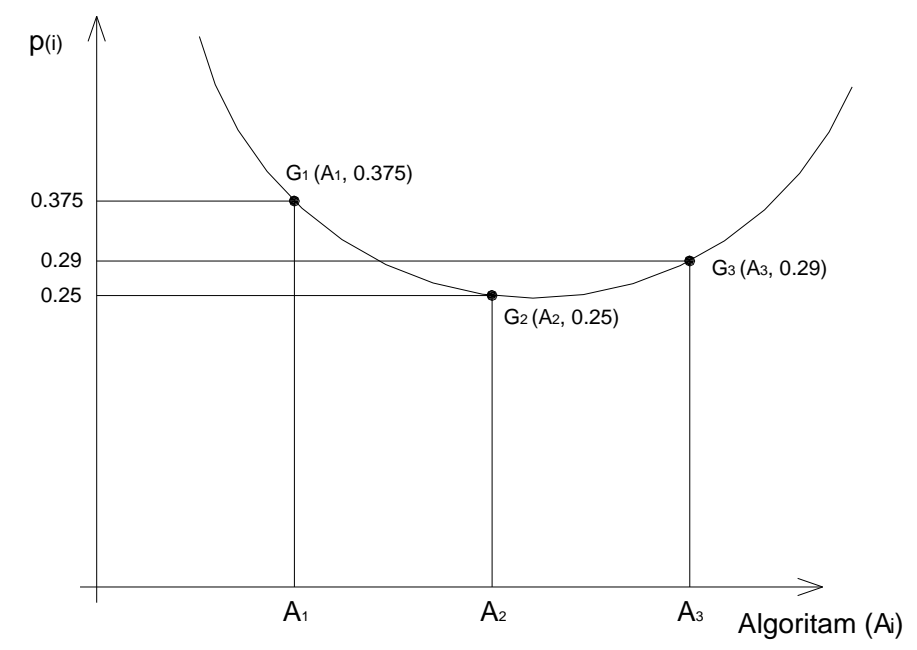

Picture 2. Curve of dependence of reengineering monitoring algorithm on the parameter significance weights engineering coefficients for the group $(3$ - II group).

STEP 9: The total mid value of algorithm weight in steps 5 , and 7 is: $p(\underline{3})=\frac{0,25+0,33}{2}=0.295$ that's the value of the question of connection between re-engineering coefficients for the group (3).

\section{Conclusion}

Mid values of algorithms, regarding the significance of total weights, are:

$$
\begin{aligned}
& p(\underline{1})=\frac{0,5+0,25}{2}=0.375, G_{1} \\
& p(\underline{2})=\frac{0,25+0,25}{2}=0.25, G_{2} \\
& p(\underline{3})=\frac{0,25+0,33}{2}=0.295, G_{3}
\end{aligned}
$$

which points to the conclusion that during the carrying out of re-engineering parameters in small or medium enterprises one should conduct the questionnaires $G_{1}$ and $G_{3}$ and then the questionnaire $G_{2}$ comprising the event parameter groups. Picture 2 represents a graphic display of the monitoring algorithm dependence curve (Sorad Dj. (1979)). . 


\section{References}

1. Adamović Z., Stefanović S., (2008). REENGINEERING OF BUSINESS PROCESSES IN SMALL AND MEDIUM ENTERPRISES, a Scientific and Expert Conference "Proactive machine maintenance" , 15th - 16th May 2008, Vrnjacka Banja.

2. Bateson J (2002). Consumer performance and quality in services. Manage. Serv. Qual., 12(4): 206-209.

3. Bonn MA (2003). Employee service quality issues, Meeting the needs of our internal customers. In Managing employee attitudes and behaviors in the tourism and hospitality industry, ed. Salih Kusluvan, Hauppauge, NY: Nova Science. pp. 433-452.

4. George WR (1990). Internal marketing organizational behaviour: A level, J. Bus. Res. 20(1): 63-70. partnership in developing customer-conscious employees at every.

5. Sefanović S., (2010). Economic effects of reengineering in small and medium enterprises, $\mathrm{PhD}$ thesis, MEGATREND UNIVERZITET, Beograd, 2010.

6. Sorad $\mathrm{Dj}$. (1979). Economic and Mathematical methods and models, the Faculty of Economics, Subotica, 1979.

7. Stefanović S., Cvejić R. (2010). Conducting projects from the aspect of mathematic modelling, ,TQM“ Centar, Zrenjanin, 2010.

8. Stefanović S., Cvetković S., Grbić N., Veljković M., (2007). Defining the minimum and maximum by using simplex method, a Scientific and Expert Conference " Development, use and maintenance of hydraulic and pneumatic components and systems", Collection of studies on $\mathrm{CD}$, no. of study HIP 45, Vršac, 16th November 2007 , ISBN 978-86-83701-08-7. 